\title{
Identificação de Características das Cooperativas Agropecuárias que Influenciam a Geração de Valor Adicionado
}

\author{
Identifying Characteristics of Agricultural Cooperatives Influencing the Generation \\ of Value Added
}

\begin{abstract}
Resumo
Esta pesquisa tem como objetivo determinar as variáveis estratégicas de agregação de valor que influenciam a geração do valor adicionado das cooperativas agropecuárias. Para tanto, empregou-se testes de diferença de médias das diferentes estratégias de agregação de valor, Mann-Whitney e Kruskal-Wallis, com dados de 76 cooperativas agropecuárias do estado do Rio Grande do Sul nos anos de 2011 e 2012. Como resultado, observou-se que as características que afetam o valor adicionado das cooperativas são a presença de agroindústria, a marca própria e apresentar como produto principal a soja. No entanto, quando os testes são realizados com o valor adicionado por cooperado, somente a presença de marca própria demonstrou-se estatisticamente diferente, entretanto a um menor nível de significância. Quando analisada a variável estratégica região, os resultados apresentam-se de forma contrária, uma vez que o valor adicionado não apresentou-se estatisticamente diferente entre as regiões, porém quando os testes são realizados com o valor adicionado por cooperado é possível verificar diferenças significativas.
\end{abstract}

Palavras-chave: Cooperativa; Valor Adicionado; Estratégia.

\begin{abstract}
This research aims to determine the strategic variables of adding value to influence the generation of value added of agricultural cooperatives. For this, we used the mean difference of the different strategies for adding value, MannWhitney and Kruskal-Wallis tests, with data from 76 agricultural cooperatives in the state of Rio Grande do Sul from 2011 to 2012. As a result, it was observed that the characteristics that affect the value added cooperatives are the presence of agribusiness, the brand itself and present the main soy product. However, when the tests are performed with the value added per cooperative, only the presence of own brand proved to be statistically different, though at a lower level of significance. Evaluating strategic variable region, the results are presented in a manner contrary, since the value added showed no statistically different between regions, but when the tests are performed with the value added by cooperating can verify significant differences.
\end{abstract}

Keywords: Cooperative; Value Added; Strategy.

Paola Richter Londero ${ }^{1}$, Sigismundo Bialoskorski Neto ${ }^{2}$

${ }^{1}$ Mestranda em Controladoria e Contabilidade; Universidade de São Paulo; Rua Canindé, 286, ap. 32, Bairro Monte Alegre,

Ribeirão Preto, São Paulo, CEP: 14051-180, Brasil - paolarlondero@gmail.com

${ }^{2}$ Professor Titular do departamento de Contabilidade; Universidade de São Paulo; São Paulo, Brasil 


\section{Introdução}

$\mathrm{D}$ e acordo com Kassai (2002), a evolução da análise das demonstrações contábeis se deu pela expansão da compreensão do relacionamento entre indicadores contábeis e financeiros e tem sido utilizada na avaliação de desempenho econômico de empresas. Entretanto, no que tange as cooperativas, a análise por meio de indicadores tradicionais é considerada precária, uma vez que as cooperativas possuem uma natureza singular, em relação às demais entidades de cunho lucrativo.

Sendo as cooperativas entidades singulares, devese buscar outros meios mais adequados e compatíveis com tais características. A Demonstração do Valor Adicionado e seus índices fornecem as cooperativas uma possibilidade de análise de seu desempenho voltada para aspectos econômicos e também sociais, com ênfase no valor adicionado e não no lucro como os demais índices de rentabilidade considerados tracionais. Entretanto, a Demonstração do Valor Adicionado e seu poder informacional não são totalmente explorados, principalmente no que tange às cooperativas.

Cosenza (2003) corrobora com tal afirmação ao destacar que pesquisadores, normatizadores e contadores ainda não despertaram para a utilidade da Demonstração do Valor Adicionado e de índices gerados por tal demonstração como fonte de informação para o processo de análise econômica, financeira e social das entidades.

Para que os índices propiciados pela Demonstração do Valor Adicionado sejam utilizados, é necessário verificar a influência que as características das cooperativas causam sobre eles, bem como de que forma a influência deve ser tratada e o possível impacto na utilização desses índices.

Sendo assim, questiona-se: quais as estratégias de agregação de valor adotadas pelas cooperativas agropecuárias que podem influenciar, significativamente, a geração do valor adicionado? Para tanto, o objetivo da pesquisa é determinar as variáveis estratégicas de agregação de valor que influenciam a geração do valor adicionado das cooperativas agropecuárias. Para atender a esse objetivo o presente trabalho apresenta, além da introdução, uma discussão teórica, em seguida, o método de investigação empregado, os resultados da pesquisa realizada e por fim, as considerações finais do presente estudo.

\section{Sociedades cooperativas a contabilida- de}

As cooperativas são consideradas entidades singulares. De acordo com Young (2008), essa singularidade com relação às demais organizações econômicas ocorre porque as cooperativas podem ser vistas como uma sociedade de pessoas, cujo objetivo é a prestação de serviços, sendo que o cooperado é visto como dono e usuário de tal sociedade, onde o controle é exercido democraticamente, o quórum da assembleia é baseado no número de associados, com um compromisso educativo, social e econômico com seus associados e empregados, e o retorno dos resultados é proporcional ao valor das operações com a cooperativa. Ademais, salienta-se que, assim como as entidades não cooperativas, as cooperativas possuem fins econômicos, no entanto, não apresentam fins lucrativos. De acordo com Bialoskorski Neto (2006), essa separação entre a finalidade econômica e lucrativa, reside no fato das cooperativas apresentarem uma distinção em sua função econômica e social.

Mesmo com tais diferencias, as cooperativas tendem a apresentar, assim como as demais organizações econômicas, relação de agência, principalmente pela presença de múltiplos principais, conhecidos como cooperados. Jensen e Meckling (1976) definem relação de agência como um contrato sob o qual uma ou mais pessoas, conhecidas como principal, emprega uma ou mais pessoas, o agente, para executar em seu nome um serviço que implique a delegação de algum poder de decisão ao agente. Ressalta-se que a delegação do poder de decisão, ou controle, ao agente por parte do principal é o fator desencadeador da relação de agência.

Nas cooperativas, a presença de múltiplos principais leva a formação de um Conselho de Administração, para qual é delegado o poder de decisão. Em alguns casos, como sugerido pela Resolução CMN 3.859/2010, ainda é necessária a presença de uma Diretoria Executiva. Segundo tal resolução, é vedada a acumulação de cargos de presidente do conselho e diretoria executiva, sendo também liberada a eleição de não associados ao cargo de Diretoria Executiva, nesses casos a relação de agência pode ser intensificada, uma vez que o principal, mesmo ainda sob posse do direito de propriedade se afasta das decisões gerenciais, sendo essas delegadas ao Conselho Administrativo ou a Diretoria Executiva.

A existência da relação de agência faz com que os custos de transação sejam elevados, ou seja, que ocorra um aumento dos custos de coordenação e controle, para evitar a desapropriação da riqueza do(s) principal(is), tendo em vista que o agente tende a agir com oportunismo devido à existência de racionalidade limitada e assimetria de informação entre as partes (MILGROM; ROBERTS, 1992).

Segundo Bialoskorski Neto, Barroso e Rezende (2012, p.76) “todas essas relações apresentam os problemas de incentivos e os custos de monitoramento". No caso das cooperativas o aumento de tais custos podem levar ao seu desaparecimento, sendo necessário avaliar até que ponto a implementação de mecanismos de controle e monitoramento geram custos menores do que a desapropriação da riqueza do principal. Por essa razão, os mecanismos desenvolvidos devem estar voltados às necessidades e especificidades das cooperativas, afim de que seus custos possam ser reduzidos.

Santos et al. (2012, p. 223) expõem que a solução 
pode estar nos "sistemas de contabilidade financeira que alimentam com informações os mecanismos de controle corporativos. A contabilidade surge para contribuir com os mecanismos de governança, reduzindo o impacto dos conflitos de agência.".

Adicionalmente, Bialoskorski Neto, Barroso e Rezende (2012, p.80) expõem que "os sistemas de gerenciamento de informações são fundamentais para reduzir os custos de agência e a assimetria de informação". Scott (2009) aponta que a contabilidade é vista como um mecanismo capaz de reduzir a assimetria de informação existente entre as partes, e com isso reduzir possíveis custos de agência vinculados à perda residual. A divulgação das informações provenientes da contabilidade permite que o cooperado seja informado do que ocorre dentro da firma, sendo capaz de auxiliar no processo de controle e minimizando a possibilidade de oportunismo exposto por parte do agente.

\section{3. Índices tradicionais de avaliação econô- mico-financeira e de valor adicionado}

Nesse sentido, em 1919, Alexandre Wall desenvolveu um modelo de análise das demonstrações contábeis por meio de índices em uma tentativa de aumentar o poder informativo das demonstrações contábeis. De acordo com Carvalho (2008), essa metodologia permitia que fosse estabelecida uma relação entre as contas contábeis por meio de determinados índices e parâmetros, com o objetivo de realizar uma análise de balanços e avaliação do aspecto econômico-financeiro das empresas. Ao passar dos anos vários estudos foram desenvolvidos em busca do aprimoramento de tais análises. Dentre eles, Altman (1968) pesquisou sobre a falência de empresas utilizando conjuntamente diversos indicadores e como resultado observou que a falência de uma organização econômica poderia ser prevista por meio das informações disponíveis no Balanço Patrimonial e seus indicadores de análise.

Tradicionalmente, os índices de avaliação econômico-financeiros são os de Liquidez Corrente, Liquidez Seca, Liquidez Geral, Rotação dos Estoques, Grau de Endividamento, Capital de Terceiros/Capital Próprio, Quociente de Imobilização, Margem Bruta, Margem Operacional, Margem Líquida, Giro do Ativo Operacional, Giro do Ativo Total, Retorno sobre o Ativo e Retorno sobre o Patrimônio Líquido (MATARAZZO, 2010; CARVALHO, 2008).

Para as organizações econômicas com fins lucrativos, a utilização de tais índices parece estar de acordo com a sua natureza e auxiliar no acompanhamento econômicofinanceiro da entidade. Entretanto, Lazzarini, Bialoskorski Neto e Chaddad (1999) apontam que, no que referem às cooperativas, as decisões econômico-financeiras são notadamente mais complexas, já que as mesmas possuem natureza diferenciada das demais entidades. De acordo com Nigai (2012) torna-se também necessário verificar se tais índices tradicionais, utilizados por entidades com fins lucrativos, ainda mantém o mesmo poder informativo e preditivo, e como se dá a interação com novos índices orientados para as características das cooperativas.

Nesse sentido, as cooperativas tendem a buscar novas ferramentas de monitoramento que sejam mais condizentes com a sua natureza. Diante desse novo desafio, os gestores começaram a utilizar a análise do valor adicionado como ferramenta gerencial, tendo em vista que o valor adicionado permite que indicadores sejam apurados e também é possível obter indicadores de análise provenientes da formação e distribuição do valor adicionado. Segundo De Luca (1991), o valor adicionado é uma boa ferramenta gerencial, pois é afetado por todos os esforços que são desenvolvidos pela empresa. No caso das cooperativas, os indicadores relacionados à análise do valor adicionado demonstraram ser uma ferramenta complementar por demonstrar o esforço organizacional e sua distribuição, sem interferir em sua natureza como a análise de índices tradicionais, os quais tendem a privilegiar a visão do lucro.

Santos et al. (2012) expõem que a Demonstração de Valor Adicionado (DVA) fornece informações úteis e necessárias para análises de investimentos, concessões de empréstimos, avaliação de subsídios dentre outras decisões relevantes para a entidade. Para Cosenza (2003, p.20), "a elaboração de indicadores econômico-financeiros, a partir do valor adicionado, resulta em um instrumento de indubitável utilidade e relevância para a avaliação da gestão econômica da empresa em geral e de seu processo produtivo em particular".

Ademais, segundo Cosenza (2003) a análise do valor adicionado por meio de índices pode ser considerada como uma fonte complementar de explicação para os aspectos relacionados com a eficiência e a produtividade alcançada por uma empresa, tendo em vista a sua inter-relação com a contribuição proporcionada por cada fator produtivo ao processo de produção. Estratégias como possuir agroindústria, marca própria, definição do local sede da entidade, e, o produto principal a ser comercializado podem levar ao aumento do valor adicionado, tendo em vista, que tais aspectos podem influenciar a produtividade da entidade. Porém no caso das cooperativas é necessário verificar se tal afirmação é possível de ser realizada.

Para tanto é necessário obter o valor adicionado, objetivando sua posterior análise. Morley (1979, p. 619) descreve em uma equação do valor adicionado pode ser expressa conforme a Equação 1.

$$
\mathrm{S}-\mathrm{B}-\operatorname{Dep}=\mathrm{W}+\mathrm{I}+\operatorname{Div}+\mathrm{T}+\mathrm{R}
$$

Onde: S - Vendas; B - Aquisição de materiais e serviços; Dep - Depreciação; W - Salários; I - Juros; Div Dividendos; T - Tributos ; R - Lucros Retidos. 
Evraert e Riahi-Belkaoui (1998) apontam que essa equação expressa o valor adicionado líquido e que o valor adicionado bruto pode ser obtido passando a depreciação para o outro lado da igualdade, como uma forma de distribuição do valor adicionado bruto. Cosenza (2003) descreve que, na primeira parte da igualdade, se identifica o modo como se gera o valor adicionado bruto e, na parte posterior pode-se visualizar a distribuição de valor entre os agentes econômicos. Dessa forma, o cálculo do valor adicionado pode ser obtido mediante a aplicação de procedimentos de subtração ou de adição, utilizando-se como ponto de partida para sua determinação a Demonstração do Resultado do Exercício (DRE).

Kroetz e Cosenza (2004) assinalam que a Demonstração de Valor Adicionado, e consequentemente, as informações vinculadas ao valor adicionado, ainda não foram adequadamente exploradas em sua total amplitude e magnitude, como um relevante instrumento para a apresentação de informação útil para os interesses dos distintos usuários. Nesse sentido, ainda há muito a se explorar sobre essa questão, principalmente nas entidades cooperativas que ainda carecem de índices econômico-financeiros adequados.

\section{Metodologia}

O estudo baseia-se em dados fornecidos pela Organização das Cooperativas do Estado do Rio Grande do Sul (Ocergs), com dados oriundos do Balanço Patrimonial e Demonstrativo de Sobras e Perdas de 76 cooperativas agropecuárias do estado no período de 2011 e 2012, totalizando 152 observações. Destaca-se que a amostra corresponde a $60 \%$ da população de cooperativas agropecuárias do Estado do Rio Grande do Sul, Brasil. A amostra não possui identificação, sendo somente fornecidas pela Ocergs informações sobre as estratégias de agregação de valor de cada cooperativa.

Ressalta-se que, com relação à amostra, foram eliminadas as cooperativas que apresentaram o patrimônio líquido negativo para evitar distorções na análise dos índices, assim como as cooperativas consideradas Cooperativas Centrais para evitar a dupla contagem dos dados, e as cooperativas que apresentavam informações de apenas um período. Também foi empregada na amostra uma análise por cluster, que, segundo Johnson e Wichern (2007), é uma importante técnica exploratória, uma vez que, ao estudar uma estrutura natural dos grupos, possibilita avaliar a dimensionalidade dos dados, identificar outliers e levantar hipóteses relacionadas à estrutura dos objetos, permitindo segregar elementos ou variáveis em grupos homogêneos internamente, heterogêneos entre si e mutuamente exclusivos, a partir de determinados parâmetros conforme uma medida de similaridade ou distância. A partir da análise de cluster foi possível verificar que duas cooperativas deveriam ser eliminadas da amostra por serem consideradas heterogêneas com relação às demais cooperativas. Destaca-se que as variáveis utilizadas para análise de cluster foram número de empregados, número de cooperados, região, produto principal, dummy agroindústria, dummy marca própria, estoque, patrimônio líquido, ativo total, ingresso - receita líquida, sobras/perdas - resultado líquido.

Para a elaboração do valor adicionado de cada cooperativa da amostra, foi calculado o valor adicionado pela sua formação e sua distribuição, assim como previsto por Morley (1979). O valor adicionado pela formação pode ser obtido pela Equação 2 considerando o plano de contas dos demonstrativos utilizados.

$$
\mathrm{VAf}=\mathrm{S}-\mathrm{B}+\mathrm{FI}-\mathrm{AE}-\mathrm{SE}-\mathrm{O}
$$

Onde: S - Vendas; B - Aquisição de materiais e serviços; FI - Receitas Financeiras; AE - Despesas Administrativas; SE - Despesas de Venda; O - Outras contas não operacionais.

Esse cálculo apresenta como limitação a incorporação da mão de obra e tributos sobre vendas referente aos custos de produção incorporados na variável aquisição de materiais e serviços, já que essa informação é retirada diretamente do custo evidenciado na Demonstração de Sobras e Perdas, no caso das cooperativas. Não é possível, na estrutura da Demonstração de Resultado de Exercício atual, dissociar esse custo da mão de obra e tributos sobre a venda dos demais elementos, entretanto, esse valor para efeitos do cálculo do valor adicionado, deveria ser considerado na distribuição do mesmo. Sendo assim, está incorporado a esse valor um resíduo que deveria estar presente no cálculo do valor adicionado pela distribuição, ilustrado na Equação 3.

$$
\mathrm{VAd}=\mathrm{W}+\mathrm{T}+\mathrm{FE}+\mathrm{DL}+\mathrm{R}
$$

Onde: W - Salários; T - Tributos ; FE - Despesas Financeiras; DL - Sobras Distribuídas; R - Lucros Retidos.

Outra limitação encontrada no cálculo do valor adicionado pelas equações mencionadas foi a presença de contas genéricas, como outros, na Demonstração de Resultado de Exercício, as quais podem distorcer o cálculo do valor adicionado. Porém, ressalta-se que tais contas representam de uma maneira geral as contas não operacionais, que no caso do valor adicionado devem ser consideradas na formação como outras receitas ou parte dos insumos adquiridos de terceiros. Ressalta-se que, em média, tal conta representa uma pequena porcentagem do dispêndio das cooperativas, o que também diminui a tendência à distorção do cálculo do valor adicionado.

Ao se comparar o valor adicionado pela formação e pela distribuição encontrou-se uma variação de 4 a $8 \%$ nos valores, sendo que tal variação pode ser explicada pelas limitações apresentadas nas contas genéricas. 
Diante disso, optou-se por utilizar o valor adicionado pela formação em função de que a não consideração do custo da mão de obra e tributos sobre a venda no valor adicionado pela distribuição tende a causar maior impacto do que na formação, além de estar mais próximo do valor adicionado de algumas cooperativas que dispõem da Demonstração de Valor Adicionado.

Para a apresentação da estatística descritiva, foram escolhidos e calculados quatorze indicadores com base nos índices mais comumente utilizados para a análise econômico-financeira, sendo eles: Liquidez Corrente (LIQ. CORR), Liquidez Seca (LIQ. SECA), Liquidez Geral (LIQ. GERAL), Rotação dos Estoques (ROT. ESTQ.), Grau de Endividamento (G.ENDIVI.), Capital de Terceiros / Capital Próprio (K3.KP), Quociente de Imobilização (QUOC.IMO), Margem Bruta (MARG.BRU), Margem Operacional (MARG.OPE), Margem Líquida (MARG. LIQ), Giro do Ativo Operacional (GR.AT.OP), Giro do Ativo Total (GIR.AT), Retorno sobre o Ativo (ROA) e Retorno sobre o Patrimônio Líquido (ROE). Ressalta-se que a explicação e fórmula de cada índice encontra-se em anexo.

Adicionalmente a análise econômico-financeira tradicional, foram calculados cinco índices relacionados ao valor adicionado, sendo eles: a riqueza criada na cooperativa por cooperado (VA/COOP.), a riqueza gerada na cooperativa por empregado (VA/EMP.), capacidade de agregação de valor por vendas (VA/VEND.LIQ), valor agregado pelo ativo, tamanho da cooperativa (VA/AT.), capacidade de agregação de valor pelo capital próprio - patrimônio liquido da cooperativa (VA/PL.MED). Utilizando tais indicadores, elaborou-se a estatística descritiva dos dados das cooperativas do Estado do Rio
Grande do Sul, apresentados na Tabela 1.

Na Tabela 1 é apresentada a estatística descritiva das 76 cooperativas da amostra, não sendo descriminados os dados por anos, tendo em vista que houve pouca alteração dos resultados obtidos em 2011 e 2012, por essa razão é apresentada a estatística descritiva de cada índice com base em 152 observações.

A amostra apresenta uma assimetria positiva no que se refere aos índices de valor adicionado, ou seja, a curva de frequência da distribuição se concentra ao lado esquerdo e alongada à direita, em função da mediana apresentar valores inferiores aos da média. Sendo assim, a média é influenciada pelos maiores valores de valor adicionado, presentes na cauda a direita da distribuição, a mediana apresentando valores inferiores à média corrobora com essa informação, já que indica que $50 \%$ dos elementos da amostra ficam abaixo deste valor estipulado.

Com base nos dados obtidos pela estatística descritiva também é possível verificar que a cooperativa que apresenta o maior valor adicionado possui como produto principal a soja, sendo que possui agroindústria e marca própria, e apresenta 5.944 cooperados e 704 empregados. Em contrapartida, a cooperativa com menor valor adicionado tem como produto principal a cebola, não tendo agroindústria e nem marca própria, com 85 cooperados e nenhum empregado.

Ao observar o valor adicionado por cooperado, a cooperativa que apresenta maior valor para essa variável tem como produto principal o arroz, tendo agroindústria e também marca própria, com 86 cooperados e 341 empregados. Já a cooperativa com menor valor adicionado por cooperado possui como produto principal a lã, apresenta agroindústria e marca própria, contando

Tabela 1 - Estatística descritiva das cooperativas do Rio Grande do Sul.

\begin{tabular}{|c|c|c|c|c|c|c|c|c|c|}
\hline & $\mathrm{n}$ & \multicolumn{2}{|r|}{ Média } & & Mediana & Desvio padrão & \multicolumn{2}{|r|}{ Mínimo } & Máximo \\
\hline LIQ.CORR & 152 & & 1,9917 & & 1,2570 & 2,5796 & & 0,1581 & 18,8608 \\
\hline LIQ.Seca & 152 & & 1,4752 & & 0,8614 & 2,2045 & & 0,1272 & 13,1830 \\
\hline LIQ.GERAL & 152 & & 1,6287 & & 1,0811 & 2,0711 & & 0,3308 & 14,9545 \\
\hline ROT.EST & 152 & & 15,1778 & & 7,5695 & 36,1079 & & 0,0000 & 261,2869 \\
\hline G.ENDIVI. & 152 & & 0,6174 & & 0,6720 & 0,2213 & & 0,0059 & 0,9869 \\
\hline K3.KP & 152 & & 3,6173 & & 2,0490 & 8,1203 & & 0,0060 & 75,3617 \\
\hline QUOC.IMO & 152 & & 1,2074 & & 0,8156 & 2,9150 & & 0,0000 & 31,1571 \\
\hline MARG.BRU & 152 & & 0,0280 & & 0,0170 & 0,0762 & & $-0,3204$ & 0,6176 \\
\hline MARG.OPE & 152 & & 0,9456 & & 0,1365 & 4,9756 & & $-0,2815$ & 58,2758 \\
\hline MARG.LIQ & 152 & & 0,0258 & & 0,0161 & 0,0748 & & $-0,3204$ & 0,6176 \\
\hline GR.AT.OP & 152 & & 2,2030 & & 1,5014 & 3,0980 & & 0,0118 & 24,0046 \\
\hline GIR.AT & 152 & & 2,1061 & & 1,4539 & 3,0967 & & 0,0112 & 24,0046 \\
\hline ROA & 152 & & 0,0763 & & 0,0339 & 0,1345 & & $-0,1756$ & 0,7989 \\
\hline ROE & 152 & & 0,1010 & & 0,0808 & 0,3145 & & $-2,4087$ & 0,9508 \\
\hline VA/VEND.LIQ & 152 & & 0,1621 & & 0,1211 & 0,1803 & & 0,0074 & 1,7513 \\
\hline VA/AT. & 152 & & 0,2338 & & 0,1664 & 0,2847 & & 0,0101 & 2,3826 \\
\hline VA/PL.MÉD & 152 & & 1,0423 & & 0,5528 & 3,3942 & & 0,0355 & 40,9580 \\
\hline VA/EMP. & 152 & $\mathrm{R} \$$ & $94.779,54$ & $\mathrm{R} \$$ & $65.603,09$ & $98.737,12$ & $\mathrm{R} \$$ & $2.246,84$ & $539.109,28$ \\
\hline VA/COOP. & 152 & $\mathrm{R} \$$ & $18.963,74$ & $\mathrm{R} \$$ & $5.638,78$ & $\mathrm{R} \$ \quad 44.095,25$ & $\mathrm{R} \$$ & 55,70 & $\mathrm{R} \$ \quad 322.760,36$ \\
\hline VA & 152 & $\mathrm{R} \$$ & $19.141 .965,76$ & $\mathrm{R} \$$ & $5.182 .351,65$ & $\mathrm{R} \$ 27.250 .583,87$ & $\mathrm{R} \$$ & $18.704,64$ & $\mathrm{R} \$ 119.298 .058,00$ \\
\hline
\end{tabular}

Fonte: elaborado pelo autor com dados fornecidos pela OCERGS. 
com 852 cooperados e 10 empregados.

Por meio desta análise pode-se perceber que para o valor adicionado as características que poderiam influenciar os resultados apresentados são agroindústria, marca própria e produto. Entretanto, quando são analisadas as informações referentes ao valor adicionado por cooperado, a presença de agroindústria e marca própria na cooperativa não são claramente observadas.

Destaca-se que os índices ROA e ROE foram calculados, entretanto, não são indicados para cooperativas (CARVALHO, 2008). Essa inadequação ocorre porque as cooperativas agropecuárias têm como objetivo atender as necessidades e aspirações econômicas de seus associados, que normalmente são obtidas por meio de um maior valor pago por seus produtos, um menor valor de venda de insumos, pela prestação de serviços e não por eventuais resultados econômicos positivos, a exemplo do lucro em outras empresas, desta forma os indicadores ROA e ROE não são indicados na análise econômica e financeira de cooperativas. Assim, as sobras expressas no Demonstrativo de Sobras e Perdas não podem ser vistas como o retorno gerado pelas cooperativas.

Outro procedimento metodológico empregado no presente artigo foi a realização de testes de médias com a finalidade de verificar diferenças significativas entre as amostras submetidas ao teste. A amostra exposta anteriormente não apresenta uma distribuição normal e por essa razão os testes empregados foram testes não paramétricos que são conhecidos como testes de livre distribuição dos dados. Para os testes que foram submetidas duas amostras independentes utilizou-se o teste não paramétrico Mann-Whitney. Já para os testes com mais de duas amostras independentes empregou-se o teste não paramétrico conhecido como Kruskal-Wallis.

\section{Resultados}

Em busca de agregação de valor e melhores índices econômico-financeiros, as cooperativas adotam estratégias diferenciadas para o alcance desse objetivo. Dentre essas estratégias estão a adoção de determinados produtos, adoção de agroindústria como meio de diversificação da produção, a utilização de marca própria, presença de agroindústria e marca própria na cooperativas simultaneamente, bem como a definição da sede da cooperativa. No presente trabalho foram selecionadas tais características estratégicas para verificar a influência sobre o valor adicionado e o valor adicionado por cooperado. A Tabela 2 demonstra um resumo a cerca das informações das variáveis selecionadas para o estudo.

A partir da análise da amostra é possível perceber que cerca de $44 \%$ das cooperativas agropecuárias do Estado do Rio Grande do Sul apresentam agroindústria, sendo que seu desempenho, baseado no valor adicionado, tende a ser melhor do que as cooperativas que não apresentam essa característica. $\mathrm{O}$ valor adicionado médio das cooperativas agroindústrias é de $\mathrm{R} \$ 28.787 .541,86$, no ano de 2011, e de R $\$ 32.199 .555,19$, em 2012. Apresentando um crescimento de $11,85 \%$, sendo que no mesmo período as cooperativas que se dedicam somente a comercialização de commodity apresentaram no mesmo período um decréscimo do valor adicionado $2,31 \%$.

Para verificar se as médias de valor adicionado das cooperativas com agroindústria são estatisticamente diferentes empregou-se o teste Mann-Whitney. A partir do teste é possível verificar que as cooperativas que apresentam agroindústria possuem médias estatisticamente diferentes das cooperativas que não possuem, a um nível de significância de $1 \%$. As cooperativas que possuem agroindústria, em média, apresentam um valor

Tabela 2 - Estatística descritiva e p-value das cooperativas por característica.

\begin{tabular}{|c|c|c|c|c|c|c|c|c|c|c|}
\hline & $\begin{array}{c}N^{\circ} \\
\text { Coop. }\end{array}$ & $\begin{array}{c}\text { Média de } \\
\text { Cooperados }\end{array}$ & & VA Médio & VA Máximo & \multicolumn{2}{|c|}{ Va Mínimo } & VA/Coop. & $\begin{array}{c}p \text {-value } \\
\text { VA }\end{array}$ & $\begin{array}{c}\text { P-value } \\
\text { VA/Coop. }\end{array}$ \\
\hline \multicolumn{11}{|c|}{ Estratégia - Agroindústria } \\
\hline Agroindústria & 33 & 3382 & $\mathrm{R} \$$ & $30.493 .548,52$ & R\$ $119.298 .058,00$ & $\mathrm{R} \$$ & $47.459,81$ & $\mathrm{R} \$ 23.591,70$ & \multirow{2}{*}{$0,000^{* * *}$} & \multirow{2}{*}{0,143} \\
\hline Sem Agroindústria & 43 & 2275 & $\mathrm{R} \$$ & $10.430 .285,97$ & $\mathrm{R} \$ \quad 65.643 .642,03$ & $\mathrm{R} \$$ & $18.704,64$ & $\mathrm{R} \$ 15.412,05$ & & \\
\hline \multicolumn{11}{|c|}{ Estratégia - Marca Própria } \\
\hline Marca Própria & 45 & 3315 & $\mathrm{R} \$$ & $26.882 .324,79$ & R\$ $119.298 .058,00$ & $\mathrm{R} \$$ & $47.459,81$ & $\mathrm{R} \$ 22.186,69$ & \multirow{2}{*}{$0,000 * * *$} & \multirow{2}{*}{$0,015^{* *}$} \\
\hline Sem Marca Própria & 31 & 1945 & $\mathrm{R} \$$ & $7.905 .960,72$ & $\mathrm{R} \$ \quad 49.521 .031,52$ & $\mathrm{R} \$$ & $18.704,64$ & $\mathrm{R} \$ 14.285,27$ & & \\
\hline \multicolumn{11}{|c|}{ Estratégia -Região } \\
\hline Região Central & 8 & 3365 & $\mathrm{R} \$$ & $9.415 .504,16$ & $\mathrm{R} \$ \quad 30.713 .079,66$ & $\mathrm{R} \$$ & $2.609 .093,45$ & $\mathrm{R} \$ \quad 3.712,51$ & \multirow{4}{*}{0,504} & \multirow{4}{*}{$0,002 * * *$} \\
\hline Região Nordeste & 12 & 1719 & $\mathrm{R} \$$ & 8.073.087,88 & R\$ $\quad 28.942 .648,03$ & $\mathrm{R} \$$ & $204.288,23$ & $\mathrm{R} \$ \quad 5.821,05$ & & \\
\hline Região da Serra & 11 & 968 & $\mathrm{R} \$$ & $22.980 .534,95$ & $\mathrm{R} \$ 110.040 .385,29$ & $\mathrm{R} \$$ & $77.522,22$ & $\mathrm{R} \$ 24.399,20$ & & \\
\hline Outras Regiões & 45 & 3361 & $\mathrm{R} \$$ & $22.884 .498,34$ & R\$ $119.298 .058,00$ & $\mathrm{R} \$$ & $18.704,64$ & $\mathrm{R} \$ 22.971,82$ & & \\
\hline \multicolumn{11}{|c|}{ Estratégia - Produto } \\
\hline Soja & 36 & 3604 & $\mathrm{R} \$$ & $23.399 .499,77$ & R\$ $119.298 .058,00$ & $\mathrm{R} \$$ & $204.288,23$ & $\mathrm{R} \$ \quad 9.098,89$ & \multirow{4}{*}{$0,002 * * *$} & \multirow{4}{*}{0,320} \\
\hline Arroz & 8 & 1245 & $\mathrm{R} \$$ & $8.067 .841,48$ & R\$ $\quad 27.757 .390,61$ & $\mathrm{R} \$$ & $349.222,94$ & $\mathrm{R} \$ 48.258,31$ & & \\
\hline Leite & 11 & 3279 & $\mathrm{R} \$$ & $18.058 .561,63$ & $\mathrm{R} \$ 110.040 .385,29$ & $\mathrm{R} \$$ & $106.818,75$ & $\mathrm{R} \$ 23.885,82$ & & \\
\hline Outros & 21 & 1604 & $\mathrm{R} \$$ & $16.629 .633,15$ & $\mathrm{R} \$ 114.301 .179,00$ & $\mathrm{R} \$$ & $18.704,64$ & $\mathrm{R} \$ 22.136,84$ & & \\
\hline
\end{tabular}

Fonte: elaborado pelo autor com dados fornecidos pela OCERGS. 
agregado cerca de 3 vezes superior do que as cooperativas que não possuem agroindústria.

Entretanto, ressalta-se que as cooperativas que possuem em agroindústria apresentam um maior número de cooperados do que aquelas com comercialização somente de commodity, em média 3.382 e 2.275 cooperados, respectivamente. Sendo assim, ao de analisar a variável valor adicionado por cooperado das cooperativas com agroindústria e sem agroindústria não é possível verificar uma diferença significativa das médias.

Com o objetivo de complementar a análise da diferença entre o desempenho das cooperativas com agroindústria e que não possuem essa característica procurouse análise três índices considerados tradicionais para avaliação do desempenho econômico-financeiro, sendo eles: índice de liquidez geral, capital de terceiros sobre capital próprio e margem líquida. Como resultado, pode-se observar que apenas o índice de liquidez geral apresentou média com diferença estatística a um nível de $5 \%$ de significância. Sendo que as cooperativas que possuem agroindústria apresentam um índice médio de 1,09 , enquanto as cooperativas que comercialização somente de commodity apresentam um índice de liquidez geral médio de 2,04.

Adicionalmente a essa análise procurou-se verificar a influência da presença da marca própria na cooperativa, tendo em vista que $60 \%$ das cooperativas da amostra apresentam essa característica. A partir do teste de médias Mann-Whitney com essa variável é possível verificar que as cooperativas que apresentam marca própria possuem médias estatisticamente diferentes das cooperativas que não possuem, a um nível de $1 \%$ de significância. As cooperativas que possuem marca própria, em média, apresentam um valor agregado de $\mathrm{R} \$ 26.882 .324,79$, enquanto as cooperativas que não possuem marca própria apresentam um valor agregado médio de $\mathrm{R} \$ 7.905 .960,72$, ou seja, 70,59\% inferior as que adotam essa estratégia.

Ao se analisar o número de cooperados das cooperativas que apresentam marca própria e das que não possuem verificou-se que as cooperativas que apresentam marca própria tendem a ter um maior número de cooperados o que pode indicar que a influência da marca própria sobre a variável valor adicionado por cooperado poderia não ser significativa. No entanto, ao se realizar tal teste, é possível verificar que as cooperativas que apresentam marca própria possuem médias estatisticamente diferentes das cooperativas que não possuem, no que se refere ao valor adicionado por cooperado, a nível de significância de $5 \%$. As cooperativas que possuem marca própria, em média, apresentam um valor agregado por cooperado de $\mathrm{R} \$ 22.186,69$, enquanto as cooperativas que não possuem marca própria apresentam um valor agregado médio de $\mathrm{R} \$ 14.285,27$.

Verificada a influência causada pela presença de agroindústria e marca significância nas cooperativas procurou-se apurar se tais características apresentadas nas cooperativas de forma combinada causariam o mesmo impacto. A partir do teste de médias Mann-Whitney é possível verificar que as cooperativas que apresentam marca própria e agroindústria possuem médias estatisticamente diferentes das cooperativas que não possuem essa característica, à um nível de 1\% de significância.

Em seguida, procurou-se verificar a influência da região onde a cooperativa encontra-se sediada sobre o valor adicionado pela mesma. O Rio Grande do Sul é dividido em 28 Conselhos Regionais de Desenvolvimento (Coredes), sendo que grande parte das cooperativas se localizam no centro, nordeste e serra do estado. Nesse teste é possível verificar que as cooperativas possuem médias estatisticamente iguais independente da região onde se encontram sediadas, não sendo esse um fator de influência no valor adicionado das cooperativas do estado. Entretanto, quando os testes são realizados com o valor adicionado por cooperado é possível verificar que as médias são estatisticamente diferentes em função das regiões onde as cooperativas encontram-se sediadas. Essa diferença é significativa quando o valor adicionado por cooperado da região central ou nordeste é comparado ao da região da serra ou outras regiões.

Outra característica que se procurou verificar foi a influencia sobre o valor adicionado dos produtos produzidos pelas cooperativas agropecuárias do estado do Rio Grande do Sul.

As $47 \%$ das cooperativas do Rio Grande do Sul possuem a soja como produto principal, $14 \%$ apresentam o leite como produto principal e $12 \%$ o arroz, além disso, há cooperativas que apresentam como produto principal suínos, uva, frutas, etc. A partir do teste de médias é possível verificar que os diferentes tipos de produtos das cooperativas influenciam o valor agregado das mesmas. Sendo que as médias são estatisticamente diferentes a um nível de significância de $1 \%$.

Diante dessa constatação, torna-se necessário identificar entre quais produtos essa diferença ocorre. Para tanto, foram realizado cinco testes combinando dois a dois os produtos principais de cada cooperativa. Ao realizar o teste entre cooperativas que possuem como produto principal a soja ou o arroz é possível verificar que as cooperativas que possuem como produto principal soja e arroz apresentam valor agregado significativamente diferente, a um nível de significância de 5\%, já que o p-value apresentado pelo teste é de 0,008. Em média as cooperativas que possuem a soja como produto principal apresentam um valor agregado médio de $\mathrm{R} \$$ 23.399.449,77 já as cooperativas que trabalham com o arroz como produto principal apresentam um valor médio de $\mathrm{R} \$$ 8.067.841,48.

Quando as cooperativas que possuem como produto principal o leite são testadas de forma combinada com as cooperativas que possuem como produto principal a soja é possível verificar resultados similares à análise daquelas cooperativas que possuem como produto principal a soja com aquelas que possuem como produto principal 
o arroz. A partir do teste de médias é possível verificar que as cooperativas que possuem como produto principal soja e leite apresentam valor agregado diferente. Sendo que as médias são estatisticamente diferentes a um nível de significância de 5\%. Em média as cooperativas que possuem a soja como produto principal apresentam um valor agregado médio de $\mathrm{R} \$ 23.399 .449$,77 já as cooperativas que trabalham com o leite como produto principal apresentam um valor médio de $\mathrm{R} \$ 18.058 .561,63$

Com a finalidade de confirmar um possível indício que as cooperativas de soja tendem a ser diferenciadas quanto ao seu valor adicionado gerado, realizou-se o teste de médias entre as cooperativas que tem como produto principal o leite ou o arroz. Esse teste apontou que as cooperativas que apresentam como produto o leite ou o arroz não apresentam diferença significativa quanto ao valor adicionado. Sendo assim, esses resultados corroboram com a ideia de que as cooperativas que apresentam como produto principal a soja possuem valor adicionado superior às cooperativas que optam por trabalhar com outros produtos.

Esses resultados voltam a ser confirmados quando os valores adicionados das cooperativas de soja são testados em conjunto as cooperativas que possuem como foco outros produtos. A partir do teste de médias é possível verificar que as cooperativas que possuem como produto principal soja e outros produtos apresentam valor adicionado diferente. Sendo que as médias são estatisticamente diferentes a um nível de significância de 1\%. Em média as cooperativas que possuem a soja como produto principal são superiores as cooperativas que trabalham com outros produtos principais e que apresentam um valor adicionado médio de $\mathrm{R} \$$ 16.629.633,15.

Diante de tal constatação procurou-se analisar as cooperativas agropecuárias que possuem a soja como produto principal. A Tabela 3 apresenta a estatística descritiva de tais cooperativas.

$\mathrm{Na}$ amostra de 76 cooperativas agropecuárias do Estado do Rio Grande do Sul, 36 cooperativas apresentam a soja como produto principal, sendo que dessas 10 cooperativas apresentam agroindústria. Já com relação à marca própria, 52,78\% das cooperativas apresentam essa característica, ressaltando que todas as cooperativas que possuem agroindústria também possuem marca própria. Essas cooperativas apresentam uma média de 3.604 cooperados e 363 empregados, bem como uma média de faturamento de $\mathrm{R} \$ 215.625 .311,20$ e uma média de ativos totais de $\mathrm{R} \$ 168.533 .449,22$.

Em uma análise comparativa com a estatística descritiva de todas as cooperativas do estado, é possível perceber que as cooperativas de soja apresentam a média dos índices de valor adicionado mais próximos à mediana, o que indica que a dispersão dos dados das cooperativas de soja é menor do que se comparada a uma análise em conjunto. As médias das variáveis valor adicionado por empregado e valor adicionado são superiores do que a média da amostra total, entretanto, a média de valor adicionado por cooperado é menor em

Tabela 3 - Estatística Descritivas das Cooperativas de Soja

\begin{tabular}{|c|c|c|c|c|c|}
\hline \multicolumn{6}{|c|}{ Cooperativas de Soja $-\mathrm{n}=36$} \\
\hline Índices & Média & Mediana & Desvio padrão & Mínimo & Máximo \\
\hline LIQ.CORR & 1,25435 & 1,16543 & 0,41619 & 0,50349 & 3,05719 \\
\hline LIQ.Seca & 0,91522 & 0,83932 & 0,41355 & 0,12895 & 2,43233 \\
\hline LIQ.GERAL & 1,06443 & 1,01543 & 0,27487 & 0,45821 & 2,14334 \\
\hline ROT.EST & 8,26214 & 7,02415 & 4,39526 & 1,42455 & 23,17396 \\
\hline G.ENDIVI. & 0,70399 & 0,71570 & 0,13296 & 0,32905 & 0,98690 \\
\hline K3.KP & 5,16876 & 2,51742 & 11,37863 & 0,49042 & 75,36168 \\
\hline QUOC.IMO & 1,48350 & 0,83515 & 4,14564 & 0,01857 & 31,15709 \\
\hline$M A R G . B R U$ & 0,02069 & 0,01460 & 0,03120 & $-0,09585$ & 0,13105 \\
\hline MARG.OPE & 0,35456 & 0,13858 & 0,37270 & $-0,14503$ & 1,33548 \\
\hline MARG.LIQ & 0,01935 & 0,01399 & 0,03038 & $-0,09585$ & 0,12733 \\
\hline GR.AT.OP & 2,27056 & 1,57631 & 3,04957 & 0,44494 & 23,28853 \\
\hline GIR.AT & 2,16871 & 1,48518 & 3,06323 & 0,34034 & 23,28853 \\
\hline$R O A$ & 0,06075 & 0,02434 & 0,10323 & $-0,17557$ & 0,43626 \\
\hline$R O E$ & 0,08151 & 0,08081 & 0,34424 & $-2,40868$ & 0,95080 \\
\hline VA/VEND.LIQ & 0,11250 & 0,10619 & 0,04896 & 0,03422 & 0,24652 \\
\hline VA/ATIVO TOTAL & 0,15937 & 0,14125 & 0,08932 & 0,03216 & 0,53637 \\
\hline$V A / P L . M E ́ D$ & 1,34252 & 0,51535 & 4,88589 & 0,10464 & 40,95800 \\
\hline$V A / E M P$ & $96.848,62$ & $77.688,23$ & $87.841,68$ & $\mathrm{R} \$ 13.110,40$ & $502.190,38$ \\
\hline$V A / C O O P$. & $9.098,89$ & $5.570,29$ & $13.553,88$ & 572,45 & $93.538,12$ \\
\hline$V A$ & $\mathrm{R} \$ 23.399 .449,77$ & R\$ $14.429 .899,90$ & $\mathrm{R} \$ 26.853 .594,83$ & $\mathrm{R} \$ 204.288,23$ & $\mathrm{R} \$ 119.298 .058,00$ \\
\hline
\end{tabular}

Fonte: elaborado pelo autor com dados fornecidos pela OCERGS. 
função das cooperativas de soja possuírem um maior número de cooperados.

Como ressaltado anteriormente, a cooperativa que apresenta maior valor adicionado dentre as 76 cooperativas possui como produto principal a soja. Essa cooperativa possui agroindústria, marca própria, média de cooperados e empregados superiores as demais cooperativas de soja. A cooperativa de soja com menor valor adicionado não apresenta agroindústria e nem marca própria, fica sediada na região nordeste e conta apenas com 1 empregado e 23 cooperados.

Das 36 cooperativas que apresentam a soja como produto principal, $94,4 \%$ apresentam outro produto, considerado secundário, normalmente arroz, trigo ou milho. Em uma análise das cooperativas de soja que possuem a soja como um único produto pode-se verificar que elas não apresentam agroindústria e também não apresentam marca própria. Como demonstrado anteriormente, a falta de presença dessas duas características apresentam valor adicionado menor, o que se confirma nesse caso. Essas cooperativas apresentam um número de empregados bem abaixo da média das cooperativas de soja que tem agroindústria, marca própria e mais de um produto e por essa razão os índices relacionados ao valor adicionado das cooperativas não apresenta diferença significativa assim como no caso dos índices econômico-financeiros tradicionais.

Como último teste complementar a análise das cooperativas agropecuárias do estado do Rio Grande do Sul com base em índices de valor adicionado procurou-se verificar se a influência do produto da cooperativa sobre o valor adicionado também poderia ser expandido da mesma forma para a variável valor adicionado por cooperado.

A partir desse teste foi possível observar que as cooperativas, independente do seu produto principal, apresentam valor adicionado por cooperado estatisticamente iguais. Essa indicação demonstra que mesmo as cooperativas que possuem como produto principal a soja, e por essa razão tendem a apresentar maior valor adicionado, no que se refere à distribuição desse valor por cooperado não é possível observar essa relação, já que tais cooperativas tendem a ter um maior número de cooperados fazendo com o valor adicionado por cooperado seja diminuído.

\section{Conclusão}

O índice de valor adicionado é proveniente da Demonstração do Valor Adicionado e pode ser considerado um índice de acompanhamento do desempenho. No caso das cooperativas, tal índice, e todos os demais índices que podem ser extraídos da Demonstração de Valor Adicionado, permitem que informações com foco econômico e social sejam consideradas, diferentemente de alguns índices tradicionais econômico-financeiros que possuem enfoque lucrativo.

Por essa razão, os índices relacionados ao valor adicionado tendem a ser mais adequados à tomada de decisão das cooperativas, sendo necessário analisar se determinadas características das cooperativas poderiam afetar a análise desempenho por esse índice. Para tanto, o objetivo da pesquisa foi determinar as variáveis estratégicas de agregação de valor que influenciam a geração do valor adicionado das cooperativas agropecuárias.

Por meio de teste de médias com amostra estratificada foi possível verificar que as cooperativas que possuem agroindústria, marca própria e como produto principal a soja, no estado do Rio Grande do Sul, tendem a apresentar um maior valor adicionado, a um nível de significância de $1 \%$. Não foi possível verificar tal relação com as variáveis estratégicas região de localização e entre os demais produtos das cooperativas agropecuárias.

Ao se observar o valor adicionado por cooperado somente é possível verificar diferença estatística entre as cooperativas que possuem marca própria e as que não apresentam essa característica estratégica, a um nível de significância de 5\%. Ademais, mesmos os testes estatísticos com relação à localização não apresentarem valor adicionado estatisticamente diferente, ao se realizar os testes com o valor adicionado por cooperado é possível encontrar médias estatisticamente diferentes já que as cooperativas sediadas na região central e nordeste apresentam valores significativamente inferiores às demais regiões.

A diferença entre os resultados dos testes realizados com valor adicionado e valor adicionado por cooperado podem ser justificados pelo maior número de cooperados entre as cooperativas que possuem agroindústria e como produto principal a soja. Nesse caso, o valor adicionado torna-se equiparado à cooperativa que não apresentam tal característica no que se refere ao valor adicionado por cooperado. Já no caso da marca própria, mesmo com um maior número de cooperados a diferença estatística permanece, porém a um menor nível de significância.

Sendo assim, as variáveis estratégicas para a agregação de valor relacionadas à presença de agroindústria, marca própria e o produto principal soja nas cooperativas agropecuárias influenciam na geração do valor adicionado das cooperativas agropecuárias. A consideração dos resultados do estudo permitem o início da investigação sobre o potencial de tais índices e a verificação de como podem auxiliar na tomada de decisão.

Para a compreensão da capacidade de informação dos índices que podem ser extraídos da Demonstração do Valor Adicionado torna-se necessário verificar se tal demonstração está adequada às singularidades e necessidades das cooperativas, apurando se melhorias poderiam ser realizadas em sua estrutura para que se possibilite um maior nível de informação e oportunidade das cooperativas utilizarem tal ferramenta para avaliação de seu desempenho, deixando de utilizar índices com fins lucrativos que não se enquadram a sua natureza 
Anexo - Lista de índices

\begin{tabular}{|c|c|c|}
\hline Índice & Equação & Explicação \\
\hline $\begin{array}{l}\text { Liquidez Corrente } \\
\text { (LIQ. CORR) }\end{array}$ & $\frac{\text { Ativo Circulante }}{\text { Passivo Circulante }}$ & $\begin{array}{l}\text { Mede a capacidade que a cooperativa } \\
\text { tem de cumprir com suas } \\
\text { responsabilidades em curto prazo. }\end{array}$ \\
\hline $\begin{array}{l}\text { Liquidez Seca (LIQ. } \\
\text { Seca) }\end{array}$ & $\frac{\text { Ativo Circulante - Estoques }}{\text { Passivo Circulante }}$ & $\begin{array}{l}\text { Mede a capacidade da cooperativa } \\
\text { absorver seus compromissos a curto } \\
\text { prazo, isto é, dentro do exercício sem } \\
\text { utilizar os seus estoques. }\end{array}$ \\
\hline $\begin{array}{l}\text { Liquidez Geral } \\
\text { (LIQ. GERAL) }\end{array}$ & $\begin{array}{c}\text { Ativo Circulante + Realizável a Longo } \\
\underline{\text { Prazo }} \\
\text { Passivo Circulante }+ \text { Passivo Não } \\
\text { Circulante }\end{array}$ & $\begin{array}{l}\text { Indica a capacidade da cooperativa } \\
\text { saldar todos os seus compromissos } \\
\text { de curto e longo prazo sem utilizar } \\
\text { seu Ativo Não Circulante. }\end{array}$ \\
\hline $\begin{array}{l}\text { Rotação dos } \\
\text { Estoques (ROT. } \\
\text { ESTQ.) }\end{array}$ & $\frac{\text { Custo da Mercadoria Vendida/Serviço }}{\text { Estoque Final }}$ & $\begin{array}{l}\text { Conhecido como índice estático de } \\
\text { rotação dos estoques, tem como } \\
\text { objetivo indicar se o estoque da } \\
\text { cooperativa é insuficiente, desejável } \\
\text { ou excessivo em relação ao volume } \\
\text { de vendas realizadas. }\end{array}$ \\
\hline $\begin{array}{l}\text { Grau de } \\
\text { Endividamento } \\
\text { (G.ENDIVI.) }\end{array}$ & $\begin{array}{l}\frac{\text { Passivo Circulante + Passivo Não }}{\text { Circulante }} \\
\text { Passivo Circulante + Passivo Não } \\
\text { Circulante + Patrimônio Líquido }\end{array}$ & $\begin{array}{l}\text { Mede o volume de recursos externos } \\
\text { necessário ao financiamento dos } \\
\text { investimentos da cooperativa a curto } \\
\text { e longo prazo. }\end{array}$ \\
\hline $\begin{array}{c}\text { Capital de } \\
\text { Terceiros / Capital } \\
\text { Próprio }(\mathrm{K} 3 . \mathrm{KP}) \\
\end{array}$ & $\begin{array}{c}\frac{\text { Passivo Circulante + Passivo Não }}{\text { Circulante }} \\
\text { Patrimônio Líquido }\end{array}$ & $\begin{array}{l}\text { Mede o volume de capital de } \\
\text { terceiros em relação ao patrimônio } \\
\text { líquido da cooperativa. }\end{array}$ \\
\hline $\begin{array}{l}\text { Quociente de } \\
\text { Imobilização } \\
\text { (QUOC.IMO) }\end{array}$ & $\frac{\text { Imobilizado }}{\text { Patrimônio Líquido }}$ & $\begin{array}{lccc}\text { Possibilita a visualização } & \text { do } \\
\text { quociente de imobilização } & \text { do } \\
\text { patrimônio líquido da cooperativa. }\end{array}$ \\
\hline $\begin{array}{l}\text { Margem Bruta } \\
\text { (MARG.BRU) }\end{array}$ & $\frac{\text { Sobras Brutas }}{\text { Receita Líquida }}$ & $\begin{array}{l}\text { Mede o volume de sobras brutas em } \\
\text { relação a receita líquida }\end{array}$ \\
\hline $\begin{array}{c}\text { Margem } \\
\text { Operacional } \\
\text { (MARG.OPE) }\end{array}$ & $\frac{\text { Sobras Operacional }}{\text { Receita Líquida }}$ & $\begin{array}{l}\text { Mede o volume de } \\
\text { operacionais em relação a receita } \\
\text { líquida. É um quociente muito } \\
\text { importante por demonstrar a } \\
\text { capacidade da cooperativa gerar } \\
\text { sobras e investir no Capital de Giro }\end{array}$ \\
\hline $\begin{array}{l}\text { Margem Líquida } \\
\text { (MARG.LIQ) }\end{array}$ & $\frac{\text { Sobras Líquidas }}{\text { Receita Líquida }}$ & $\begin{array}{l}\text { Demonstra o volume de resultados } \\
\text { líquidos que a cooperativa obteve } \\
\text { durante o exercício com as operações } \\
\text { realizadas. }\end{array}$ \\
\hline $\begin{array}{l}\text { Giro do Ativo } \\
\text { Operacional } \\
\text { (GR.AT.OP) }\end{array}$ & $\begin{array}{l}\text { Receita Líquida } \\
\text { Ativo Médio Operacional }\end{array}$ & $\begin{array}{l}\text { Demonstra quantas vezes o Ativo } \\
\text { menos o realizável a longo prazo, } \\
\text { menos a depreciação, se renovou } \\
\text { pelas vendas. }\end{array}$ \\
\hline $\begin{array}{l}\text { Giro do Ativo Total } \\
\text { (GIR.AT) }\end{array}$ & $\frac{\text { Receita Líquida }}{\text { Ativo Total Médio }}$ & $\begin{array}{l}\text { Demonstra quantas vezes o Ativo } \\
\text { Total se renovou pelas vendas. }\end{array}$ \\
\hline
\end{tabular}

Fonte: Carvalho (2008); Matarazzo (2010). 
Dessa forma outras pesquisas são necessárias para a continuidade desse trabalho.

\section{Bibliografia}

ALTMAN, E. I. Financial ratios, discriminant analysis and the prediction of corporate bankruptcy. Jornal of Finance, Chicago, v. XXIII, n. 4, p.589-609, 1968.

BIALOSKORSKI NETO, S.; BARROSO, M. F. G.; REZENDE, A. J. Co-operative governance and management control systems: an agency costs theoretical approach. Brazilian Business Review, Vitória, v. 9, n.2, p. 72-92, 2012.

BIALOSKORSKI NETO, S. Aspectos econômicos das cooperativas. Belo Horizonte/MG: Mandamentos, 2006.

BRASIL. Resolução CMN 3.859, 27 de maio de 2010. Constituição, a autorização para funcionamento, o funcionamento, as alterações estatutárias e o cancelamento de autorização para funcionamento de cooperativas de crédito. Disponível em: <http:// www.bcb.gov.br/pre/normativos/res/2010/pdf/ res_3859_v5_P.pdf> Acesso em 02 de jun. 2014.

CARVALHO, F. L. Indicadores de avaliação de desempenho de cooperativas agropecuárias: um estudo em cooperativas paulistas. Revista de Organizações Rurais \& Agroindustriais, Lavras, v.10, n.3, p. 420-437, 2008.

COSENZA, J. P. A eficácia informativa da Demonstração do Valor Adicionado. Revista Contabilidade \& Finanças - USP, São Paulo, Edição Comemorativa, p. 7 - 29, 2003.

DE LUCA, M. M. M. Demonstração do Valor Adicionado. 1991. Dissertação (Mestrado em Controladoria e Contabilidade) - Programa de Pósgraduação em Ciências Contábeis, Departamento de Contabilidade e Atuária, Faculdade de Economia, Administração e Contabilidade, Universidade de São Paulo, São Paulo, 1991.

JENSEN, M. C.; MECKLING, W. H. Theory of the firm: Managerial Behavior, Agency Cost and Ownership Structure. Journal of Financial Economics, New York, v. 3, n.4, p. 305-360, 1976.

JOHNSON, R. A.; D. W. WICHERN. Applied Multivariate Statistical Analysis. Sixth Edition. Upper Saddle River, New Jersey: Pearson Prentice Hall, 2007.
KASSAI, S. Utilização da Análise Envoltória de Dados na Análise das Demonstrações Contábeis. 2002. Tese (Doutorado em Controladoria e Contabilidade) - Programa de Pós-graduação em Ciências Contábeis, Departamento de Contabilidade e Atuária, Faculdade de Economia, Administração e Contabilidade, Universidade de São Paulo, São Paulo, 2002.

KROETZ, C. E.; COSENZA, J. P. Considerações sobre a eficácia do valor adicionado para a mensuração do resultado econômico e social. Revista do Conselho Regional de Contabilidade do Paraná, Curitiba, v.138, n.1, p. 28-36, 2004.

\section{LAZZARINI, S. G.; BIALOSKORSKI NETO, S.;} CHADDAD, F. R. Decisões financeiras em cooperativas: fontes de ineficiência e possíveis soluções. Revista Gestão \& Produção, v.6, n.3, p. 257-268. 1999.

MATARAZZO, D. C. Análise Financeira de Balanços: Abordagem básica e gerencial. $7^{\text {a }}$ edição. São Paulo: Atlas, 2010.

MILGROM, P.; ROBERTS, J. Economics, Organization \& Management. New Jersey: Prentice Hall, 1992.

MORLEY, M. F. The Value Added Statement in Britain. The Accounting Review, Sarasota, v. 54, n.3, p. 618-629, 1979.

NIGAI, C. A Demonstração do Valor Adicionado como instrumento de transparência nas entidades do terceiro setor. 2012. Dissertação (Mestrado em Controladoria e Contabilidade) - Programa de Pósgraduação em Ciências Contábeis, Departamento de Contabilidade e Atuária, Faculdade de Economia, Administração e Contabilidade, Universidade de São Paulo, São Paulo, 2012.

EVRAERT, S.; RIAHI-BELKAOUI, A. Usefulness of Value Added Reporting: a review and synthesis of the literature. Managerial Finance, v. 24, n. 11, 1998, p. 1-15.

SANTOS, A.; GOUVEIA, F. H. C.; VIEIRA, P. dos S. Contabilidade das sociedades cooperativas: aspectos gerais e prestação de contas. $2^{\underline{a}}$ ed. São Paulo: Atlas, 2012.

SCOTT, W. R. Financial Accounting Theory. 5th Ed. USA: Pearson Prentice Hall, 2009.

YOUNG, L. H. B. Sociedades cooperativas: resumo prático. 8ª ed. Curitiba: Juruá, 2008. 